\title{
Anticoagulation intensity and outcomes among patients prescribed oral anticoagulant therapy: a systematic review and meta-analysis
}

\author{
Natalie Oake MSc, Alison Jennings MA, Alan J. Forster MD MSc, Dean Fergusson PhD, \\ Steve Doucette MSc, Carl van Walraven MD MSc
}

\section{ABSTRACT}

Background: Patients taking oral anticoagulant therapy balance the risks of hemorrhage and thromboembolism. We sought to determine the association between anticoagulation intensity and the risk of hemorrhagic and thromboembolic events. We also sought to determine how under- or overanticoagulation would influence patient outcomes.

Methods: We reviewed the MEDLINE, EMBASE, Cochrane Central Register of Controlled Trials and CINAHL databases to identify studies involving patients taking anticoagulants that reported person-years of observation and the number of hemorrhages or thromboemboli in 3 or more discrete ranges of international normalized ratios. We estimated the overall relative and absolute risks of events specific to anticoagulation intensity.

Results: We included 19 studies. The risk of hemorrhage increased significantly at high international normalized ratios. Compared with the therapeutic ratio of $2-3$, the relative risk (RR) of hemorrhage (and 95\% confidence intervals [Cls]) were $2.7(1.8-3.9 ; p<0.01)$ at a ratio of $3-5$ and $21.8(12.1-39.4 ; p<0.01)$ at a ratio greater than 5 . The risk of thromboemboli increased significantly at ratios less than 2 , with a relative risk of $3.5(95 \% \mathrm{Cl}$ $2.8-4.4 ; p<0.01)$. The risk of hemorrhagic or thromboembolic events was lower at ratios of 3-5 (RR 1.8, 95\% Cl 1.2-2.6) than at ratios of less than 2 (RR 2.4, 95\% Cl $1.9-3.1 ; p=0.10)$. We found that a ratio of $2-3$ had the lowest absolute risk (AR) of events (AR 4.3\%/yr, 95\% Cl $3.0 \%-6.3 \%)$.

Conclusions: The risks of hemorrhage and thromboemboli are minimized at international normalized ratios of 2-3. Ratios that are moderately higher than this therapeutic range appear safe and more effective than subtherapeutic ratios.

Une version française de ce résumé est disponible à l'adresse www.cmaj.ca/cgi/content/full/179/3/235/DC1

CMAJ 2008;179(3):235-44
$\mathrm{O}$ ral anticoagulant therapy is essential for the treatment and prevention of many thromboembolic disorders. Since anticoagulants can cause serious adverse events, ${ }^{1-3}$ physicians monitor the international normalized ratios of patients taking these drugs to ensure that their ratios fall within a target range.

An international normalized ratio of 2-3 is the most common target range. Results of previous studies revealed an increased risk of bleeding among patients whose ratios exceeded 4 , an increased risk of stroke among patients whose ratios were 1.5-2 and a decreased risk of stroke at a ratio of 2.4. ${ }^{4,5}$ However, the evidence supporting the range of 2-3 has some deficiencies. We sought to determine whether the risk of hemorrhagic and thromboembolic events is minimized at an international normalized ratio of 2-3 among patients taking anticoagulants. In addition, it has been observed that patients spend more time with a ratio below 2 than above 3., The impact of such systematic underanticoagulation on patient outcomes is unknown. We sought to determine the effect of under- or overanticoagulation on the risk of thromboemboli and hemorrhage.

\section{Methods}

\section{Data sources}

We searched MEDLINE (1966-2006) for potentially pertinent studies. We then modified our strategy to include EMBASE (1980-2006), the Cochrane Central Register of Controlled Trials (1980-2006) and CINAHL (1982-2006) databases. We manually searched references in the Science Citation Index. Our search strategy is outlined in Appendix 1 (available at www.cmaj.ca/cgi/content/full/179/3/235/DC2).

\section{Study selection}

We reviewed the full text of studies involving patients taking oral anticoagulant therapy that captured hemorrhagic or

From the Department of Medicine, University of Ottawa, and the Clinical Epidemiology Program, Ottawa Health Research Institute (Oake, Jennings, Forster, Fergusson, Doucette, van Walraven), Ottawa, Ont.; and the Institute for Clinical Evaluative Sciences (van Walraven), Toronto, Ont. 
thromboembolic events. We included studies if they reported the number of hemorrhages or thromboemboli that occurred, along with the corresponding person-years of observation in at least 3 ranges of international normalized ratios $(<2,2-3$ and $>3$ ). We included studies irrespective of therapeutic indication, target range of international normalized ratios, duration of anticoagulant use, type of anticoagulant used or treatment setting.

\section{Data abstraction and study quality}

We abstracted data for groups of patients who received anticoagulants alone. We excluded data for patients who received antiplatelet medications with their anticoagulants because their risk of hemorrhagic events was significantly higher than that of patients who received anticoagulants alone. ${ }^{8.9}$ Two of us (N.O. and A.J.) independently abstracted the data, and we resolved discrepancies by committee. We abstracted data presented in graphs by using previously described methods, ${ }^{10}$ which recommend enlarging graphics.

To determine the overall relative risk (RR) and absolute risk of hemorrhage or thromboemboli by range of international normalized ratios, we required data for both the events and the person-years of observation. First, we abstracted the number of hemorrhages and thromboemboli that occurred in each range of ratios, along with the types of events captured and the criteria required for each. If studies reported events by severity, we included all but those classified as "minor." Second, we abstracted the person-years of observation for each range of ratios. We then grouped events and person-years of observation by range of international normalized ratios (i.e., $<2,2-3,3-5$ and $>5$ ). These 4 ranges reflect the most common categorizations in the eligible studies. We could not analyze the international normalized ratio as a continuous variable since we did not have access to the primary data for each study. We assigned to the " $3-5$ " range the events and corresponding person-years of observation reported for ratios that exceeded 3, that fell between 3 and 4.5 or that fell between 3 and 5. Similarly, we assigned to the "> 5" range the data reported for ratios that exceeded 4.5 or 5 .

We abstracted additional information to gauge the internal validity of eligible studies. For the number of events reported in each range of international normalized ratios, we abstracted the criteria for assigning events to a particular range, the number of events that were not assigned to a range, and the followup methods used to identify events (because the number of events identified is dependent on the intensity of patient follow-up ${ }^{11-13}$ ). For the person-years of observation at reported ranges, we determined what method of imputation was used to calculate person-years of observation (since some imputation methods are superior to others ${ }^{14}$ ). We also ascertained whether measurements taken outside of the study centre were captured (since failure to capture all ratios results in inaccurate estimates of the patient observation time at reported ranges $^{14}$ ).

\section{Statistical analysis}

For each study, we calculated the hemorrhagic and thromboembolic rates specific to 4 ranges of international normalized ratios based on the number of events at each ratio range divided by the person-years of observation assigned to that range. Using the range of 2-3 as the reference category, we calculated the relative and absolute risks of hemorrhagic, thromboembolic and combined events for ranges less than 2, 3-5 and greater than 5 . We used negative binomial regression with generalized estimating equation methodology because of the overdispersion that we observed when using Poisson distribution. ${ }^{15}$ Generalized estimating equation methodology was used to account for clustering of rates for the different ranges of ratios within each study..$^{16-18}$ We used an exchangeable correlation structure in the generalized estimating equation model, which assumed that the correlations were equal across all measurements within the independent studies. ${ }^{16}$ We weighted the studies by the logarithm of their total person-years of observation assigned to international normalized ratios. We calculated the $95 \%$ confidence intervals (CIs) for the absolute and relative risks using critical values based on the Poisson distribution. ${ }^{19}$

We expected the absolute risk of thromboembolic events to vary by patient population, with the risks possibly being higher among patients with atrial fibrillation or valvular heart disease than among other patients taking anticoagulants. Therefore, we recalculated rates of thromboembolic events after grouping studies based on the most common indication for anticoagulation. We classified studies in which more than $70 \%$ of patients had atrial fibrillation or valvular heart disease as having a focus on these diseases. We used the BreslowDay test to measure heterogeneity of event rates among the studies.

\section{Sensitivity analysis}

We conducted 5 sensitivity analyses to examine the robustness of the results of our generalized estimating equation model. First, few nonintracranial hemorrhages secondary to warfarin lead to death or disability, whereas intracranial hemorrhages have an impact on health that is similar to ischemic strokes. ${ }^{20,21}$ For this reason, we conducted a subanalysis of studies that limited their analyses to severe hemorrhagic events, including intracranial hemorrhages and fatal hemorrhages. ${ }^{21-23}$

Second, it is possible that the indication for oral anticoagulant therapy could influence results. Therefore, we conducted a subanalysis of studies involving only patients who required anticoagulation for atrial fibrillation, venous thromboembolic disease or atherosclerotic disease, including cerebrovascular disease, coronary artery disease and peripheral vascular disease.

Third, 6 of the eligible studies reported a maximum range of international normalized ratios greater than $3{ }^{24-29}$ For our base analysis, we grouped the person-years of observation and events from these studies in the ratio category of 3-5. We repeated our analysis after imputing the person-years of observation and the number of events that occurred when the ratio exceeded 5 . We used the studies with complete information to determine the mean proportion of events and personyears of observation that actually occurred at a ratio greater than 5. To impute data for the 6 eligible studies, we multiplied the mean proportion of events and person-years of observation by the number of events and time actually reported for the "> 3" range.

Fourth, we conducted a sensitivity analysis that excluded 
studies containing the greatest number of events to investigate whether the results changed after their removal.

Finally, we looked for possible interactions between the association of the international normalized ratio and event risk with potential confounders, including the indication for oral anticoagulant therapy, the type of anticoagulant prescribed and the presence of cancer or renal failure.

\section{Results}

\section{Study identification and selection}

Our search returned 2763 citations. Of those, we retrieved 263. We excluded 246 studies because they did not report the number of events or person-years of observation for 3 or more ranges of international normalized ratios, included previously reported data or reported ranges that did not fit into the 4 ranges in our study. ${ }^{30,31}$ We identified 2 additional studies by manually searching references on the Science Citation Index (Figure 1).

We included 19 studies published between 1992 and 2007 in our analysis ${ }^{6,21-29,32-40}$ (Table 1). Of these, 14 reported both hemorrhagic and thromboembolic events, ${ }^{6,21,23,25,27-29,32-37,39} 3$ reported only hemorrhagic events, ${ }^{22,38,40}$ and 2 reported only thromboembolic events. ${ }^{24,26}$ Half were retrospective cohort studies and two-thirds (68\%) were community-based studies. Warfarin was the only anticoagulant used in 9 of the studies. Six of the studies included patients with various indications for oral anticoagulant therapy, including atrial fibrillation, venous thromboembolism and ischemic heart disease.

The 19 studies involved a total of 80713 patients and accounted for 98900 person-years of observation. The number of patients in each study ranged from $55^{24}$ to $42451 .{ }^{22}$ Overall, 35514 (44\%) of the patients were female. Study characteristics are outlined in Table 1 and Appendix 2, available online at www.cmaj.ca/cgi/content/full/179/3/235/DC2.

\section{Study quality}

The type of events captured and the criteria required for each varied somewhat among the studies (Appendix 3, available online at www.cmaj.ca/cgi/content/full/179/3/235/DC2). We considered hemorrhagic events to be clinically overt hemorrhaging that resulted in hospital admission, blood transfusion or surgery; however, 2 studies restricted events to uncommon hemorrhagic events, including intracranial hemorrhage ${ }^{21}$ and fatal hemorrhages. ${ }^{22}$ Thromboembolic events most commonly included strokes, myocardial infarction and systemic emboli.

Of the 19 included studies, 13 reported ranges of international normalized ratios that fit into the 4 categories in our study. ${ }^{6,21-23,32-40}$ The remaining studies reported ranges that fit only into 3 categories because their maximum range was a ratio greater than $3 .^{24-29}$

Studies differed in the methods used to identify hemorrhagic and thromboembolic events and assign them to ranges of international normalized ratios. To identify events, 12 studies used follow-up visits, ${ }^{23,25-28,32-34,36-39} 4$ used medical record review alone,,$^{24,29,35,40}$ and 3 used administrative databases, including those for billing claims, ${ }^{21}$ discharge abstracts ${ }^{6}$ and deaths. ${ }^{22}$ To assign events to a range, 4 studies used only ratios measured at the time of the event. . $22,28,39$ If ratios at the time of the events were unavail- able, 15 studies assigned events to a range using previous measurements, taken from 2 days $^{32}$ to as many as 28 days $^{36,39}$ before the event. ${ }^{6,21,23,25,26,29,32-40}$ Half of the studies excluded at least one event because they could not be assigned to a range.

Details regarding the person-years of observation also varied among the studies. Fifteen studies used linear interpolation (i.e., placing a line between determined values) to impute values for days between measured ratios. ${ }^{6,21,23-26,28,29,32-35,37,38,40}$ The remaining studies used equidivision ${ }^{27,36}$ (i.e., assigning the first ratio to the first half of the period between measured ratios and assigning the second ratio to the last half of the period) or did not report an imputation method. ${ }^{22,24}$ Finally, only 3 studies captured all measures of ratios (including those measured outside of the regular monitoring clinic)..$^{22,33,37}$

\section{International normalized ratios and event rates}

Absolute rates of hemorrhagic and thromboembolic events differed greatly among the studies (Appendix 4, available online at www.cmaj.ca/cgi/content/full/179/3/235/DC2). Rates of hemorrhagic events in 13 studies increased with higher international normalized ratios. ${ }^{6,21-23,27-29,32,35-37,39,40}$ Four studies reported a curvi-

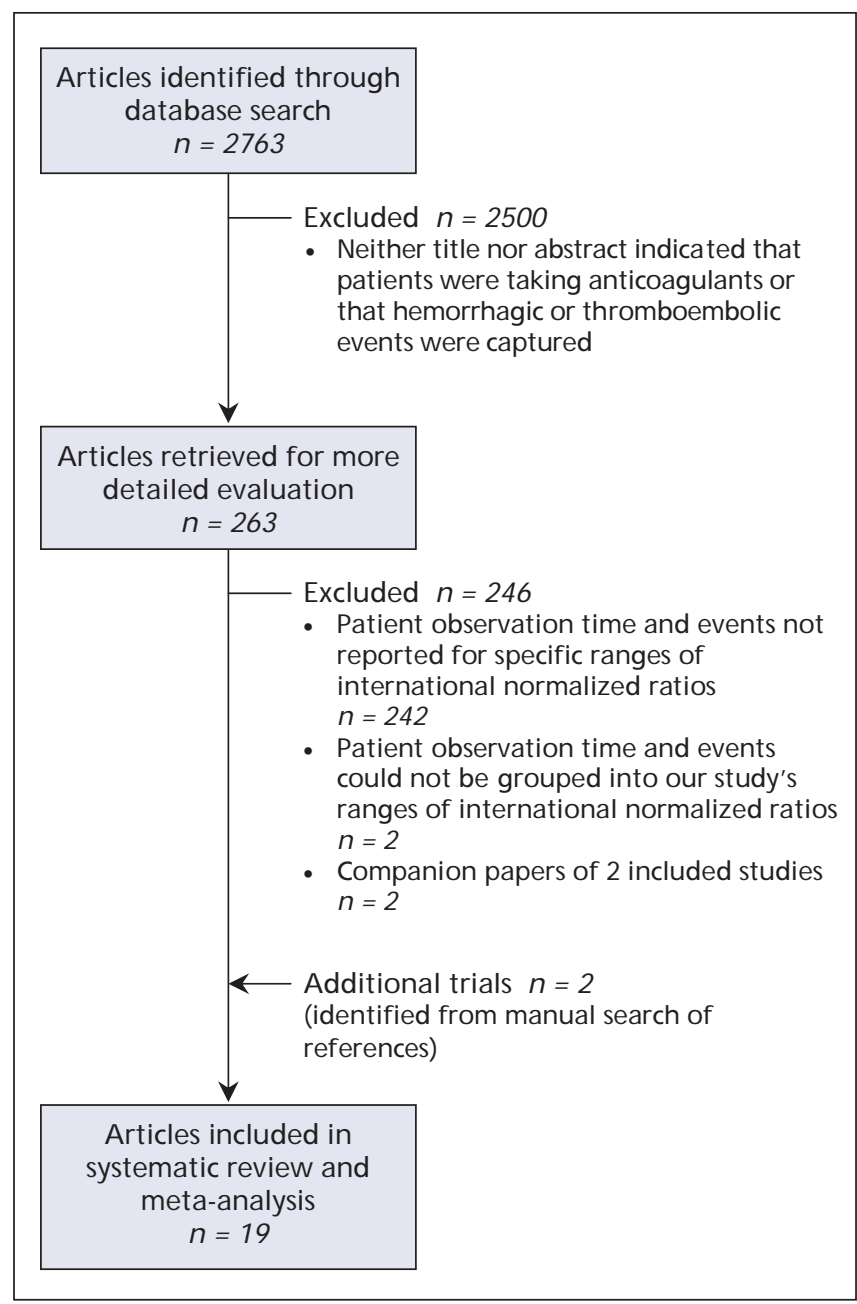

Figure 1: Retrieval and selection of studies involving patients taking oral anticoagulants that captured hemorrhagic or thromboembolic events and person-years of observation. 
linear association, where rates of hemorrhagic events associated with ratios less than 2 exceeded the rates associated with ratios between 2 and 3..$^{25,33,34,38}$ Rates of thromboembolic events in
9 studies increased with lower ratios..$^{24-29,33,37,39}$ Seven studies reported a curvilinear association, where rates of thromboembolic events increased when ratios exceeded 5.,21,23,32,33,35,36

Table 1: Characteristics of 19 studies included in our systematic review and meta-analysis of anticoagulation intensity and risk of hemorrhagic and thromboembolic events*

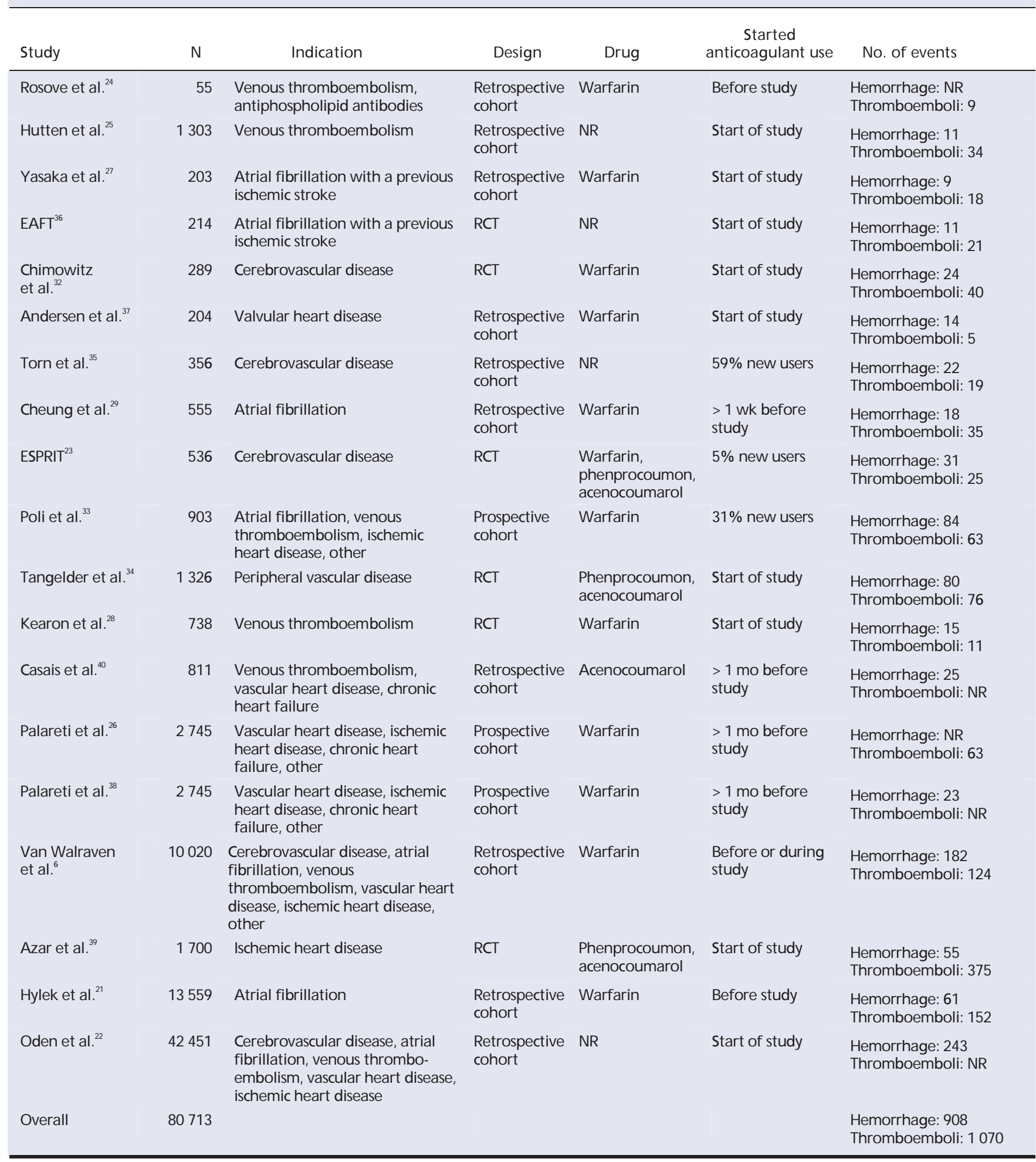

Note: EAFT = European Atrial Fibrillation Trial Study Group, ESPRIT = European and Australian Stroke Prevention in Reversible Ischaemia Trial, NR = not reported, $\mathrm{RCT}=$ randomized controlled trial.

*A more detailed version of this table appears in Appendix 2, available at www.cmaj.ca/cgi/content/full/179/3/235 /DC2. 


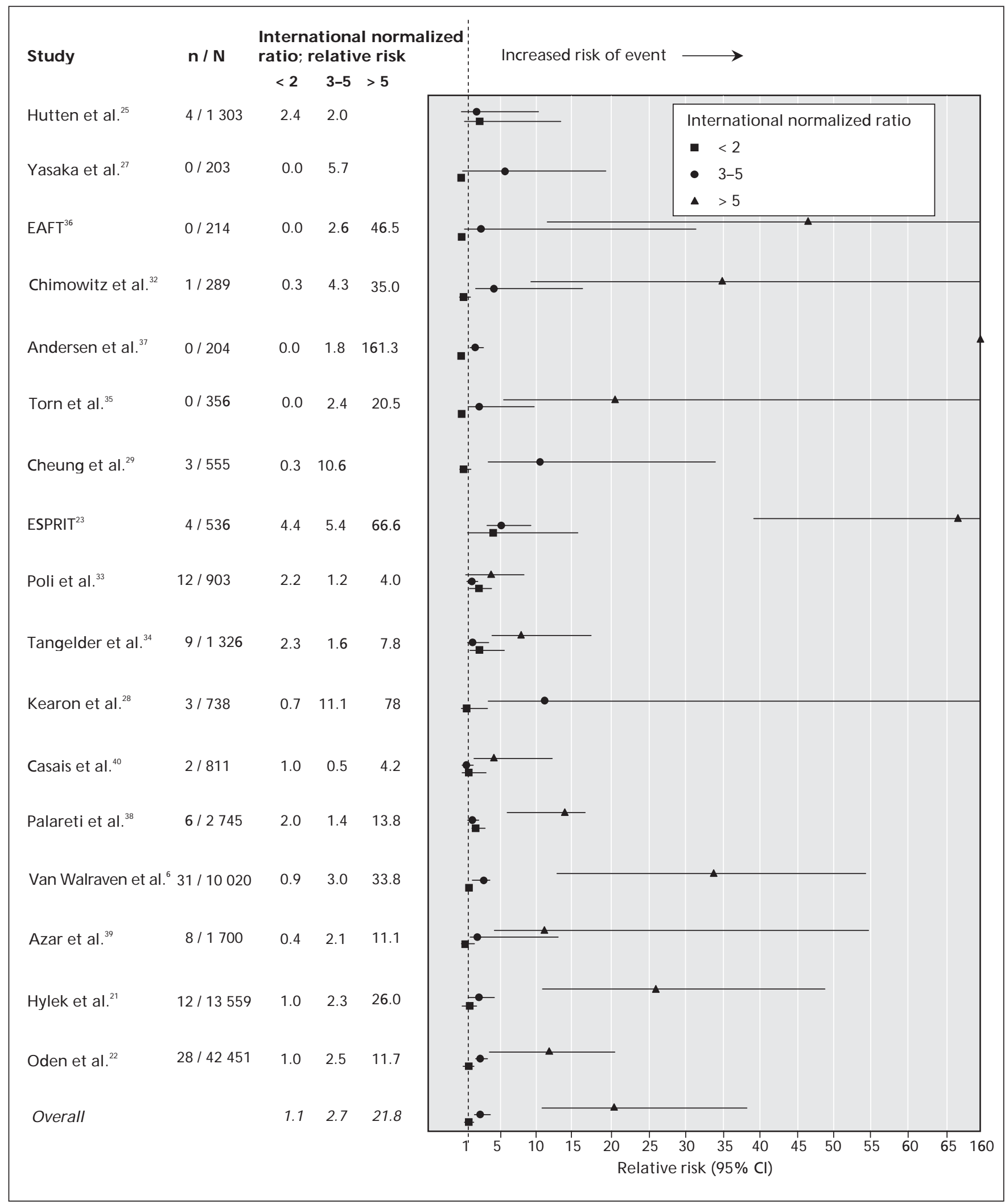

Figure 2: Anticoagulation intensity and risk of hemorrhagic events. An international normalized ratio of 2-3 was the reference range. Studies that did not report events at a ratio greater than 5 reported a maximum range of ratio greater than 3 . We grouped these data into the range of 3-5. $\mathrm{Cl}=$ confidence interval, EAFT = European Atrial Fibrillation Trial Study Group, ESPRIT = European and Australian Stroke Prevention in Reversible Ischaemia Trial, RR = relative risk. Confidence intervals are in Appendix 5, available online at www.cmaj.ca/cgi/content/full/179/3/235/DC2. 
Our negative binomial regression model showed that the overall relative risk of hemorrhage increased significantly as international normalized ratios increased (Figure 2, Table 2; Appendix 5, available online at www.cmaj.ca/cgi/content/full /179/3/235/DC2). Compared with ratios of 2-3, the relative risk of hemorrhagic events (and 95\% CIs) was 2.7 (1.8-3.9; $p<0.01)$ for ratios of $3-5$ and $21.8(12.1-39.4 ; p<0.01)$ for ratios greater than 5 . These results translated to absolute risks (and 95\% CIs) of 3.7\%/yr (2.2\%-6.3\%) for ratios of 3-5 and $30.1 \% / \mathrm{yr}(14.9 \%-60.9 \%)$ for ratios greater than 5, compared with a rate of $1.4 \% / \mathrm{yr}(0.9 \%-2.3 \%)$ for ratios of $2-3$.

The risk of thromboemboli increased significantly with low international normalized ratios (Figure 3, Table 2; Appendix 5). Compared with ratios of 2-3, the relative risk of thromboemboli (and 95\% CI) associated with ratios less than 2 was $3.5(2.8-4.4 ; p<0.01)$. The risk of thromboemboli also increased when ratios exceeded 5 (RR 2.6, 95\% CI 1.3-5.1; $p<0.01$ ). Overall, the absolute risk (and 95\% CI) of thromboembolic events was $2.6 \% / \mathrm{yr}(1.8 \%-3.6 \%)$ for ratios of $2-3$, compared with $9.0 \% / \mathrm{yr}(6.1 \%-13.4 \%)$ for ratios less than 2 and $6.6 \% / \mathrm{yr}(3.2 \%-13.9 \%)$ for ratios greater than 5 . The risk of thromboembolic events for studies that focused on patients with atrial fibrillation or valvular heart disease are given in Table 2.

After we combined hemorrhagic and thromboembolic events, our results showed that an international normalized ratio of 2-3 was significantly safer than all other ranges of ratios (Figure 4, Appendix 5). The model showed a strong curvilinear association between the ratio and the combined risk of hemorrhage and thromboemboli (Table 2). We found that a ratio of 2-3 had the lowest absolute risk of events (RR $4.3 \% / \mathrm{yr}, 95 \%$ CI $3.0 \%-6.3 \%$ ). The next safest ratio was 3-5 (RR 1.8, 95\% CI 1.2-2.6). The risk of an event was lower at this ratio than at a ratio less than 2 (RR 2.4, 95\% CI 1.9-3.1) but was not statistically significant $(p=0.10)$.

The results of the Breslow-Day test for heterogeneity among studies for both types of events were significant $(p<0.001)$. This finding indicated varying interstudy rates of hemorrhagic and thromboembolic events that exceeded what would reasonably be expected by chance.

\section{Sensitivity analyses}

We obtained results similar to those mentioned earlier when we limited our analysis to studies that included only intracranial or fatal hemorrhages (Appendix 6, available online at www.cmaj.ca/cgi/content/full/179/3/235/DC2). Our results showed a curvilinear association between anticoagulation intensity and risk of event, with a ratio of 3-5 being the safest nontherapeutic range. In fact, we found that the relative risk associated with a ratio of 3-5 was significantly lower than that for a ratio less than 2. Our results did not change significantly when we limited our analysis to studies that involved only patients with atherosclerotic disease, atrial fibrillation or venous thromboembolism (Appendix 7, available online at www.cmaj.ca/cgi/content/full/179/3/235/DC2).

Our model results did not change significantly when we imputed data for ratios greater than 5 for the 6 studies that did not report the number of events and person-years of observa-

Table 2: Association of anticoagulation intensity with risk of hemorrhagic and thromboembolic events*

\begin{tabular}{|c|c|c|c|c|c|}
\hline Outcome & \multicolumn{5}{|c|}{ International normalized ratio; risk of event } \\
\hline \multicolumn{6}{|l|}{$\begin{array}{l}\text { Hemorrhagic event } \\
(n=1777913)\end{array}$} \\
\hline Relative risk (95\% CI) & $1.1(0.7-1.7)$ & 1.0 (ref) & $2.7(1.8-3.9)$ & 21.8 & $(12.1-39.4)$ \\
\hline Absolute risk $(95 \% \mathrm{Cl}), \% / \mathrm{yr}$ & $1.5(0.7-3.0)$ & $1.4(0.9-2.3)$ & $3.7(2.2-6.3)$ & 30.1 & $(14.9-60.9)$ \\
\hline Relative risk $(95 \% \mathrm{Cl})$ & $3.5(2.8-4.4)$ & 1.0 (ref) & $0.9(0.6-1.3)$ & 2.6 & $(1.3-5.1)$ \\
\hline \multicolumn{6}{|l|}{ Absolute risk $(95 \% \mathrm{Cl}), \% / \mathrm{yr}$} \\
\hline $\begin{array}{l}\text { Studies with a focus on atrial fibrillation or } \\
\text { valvular heart diseaset }(n=514735)\end{array}$ & $8.1(4.3-15.1)$ & $2.4(1.2-4.9)$ & $2.7(1.2-6.2)$ & 7.3 & $(3.9-13.6)$ \\
\hline Other studies ( $n=1119971)$ & $10.3(6.6-16.2)$ & $2.9(2.1-4.0)$ & $2.4(1.6-3.5)$ & 7.7 & $(3.2-18.6)$ \\
\hline \multicolumn{6}{|l|}{$\begin{array}{l}\text { Combined events } \\
(n=1431906)\end{array}$} \\
\hline Relative risk $(95 \% \mathrm{Cl})$ & $2.4(1.9-3.1)$ & 1.0 (ref) & $1.8(1.2-2.6)$ & 11.9 & $(6.0-23.4)$ \\
\hline \multicolumn{6}{|l|}{ Absolute risk $(95 \% \mathrm{Cl}), \% / \mathrm{yr}$} \\
\hline $\begin{array}{l}\text { Studies with a focus on atrial fibrillation or } \\
\text { valvular heart diseaset }(n=514735)\end{array}$ & $5.1(2.9-8.9)$ & $2.5(1.2-5.2)$ & $5.0(2.1-11.7)$ & 62.0 & $(21.8-175.7)$ \\
\hline Other studies ( $n=1119971)$ & $13.7(8.6-21.9)$ & $5.3(3.7-7.6)$ & $8.0(5.1-12.3)$ & 50.3 & $(25.5-99.3)$ \\
\hline All studies & $10.6(6.7-16.6)$ & $4.3(3.0-6.3)$ & $7.0(4.5-10.8)$ & 52.3 & $(29.6-92.3)$ \\
\hline
\end{tabular}

*We calculated relative risk using an international normalized ratio of 2-3 as the reference range.

†At least $70 \%$ of patients had atrial fibrillation or valvular heart disease. 
tion for this range. Our model results were also robust when we excluded the studies reporting the most events. The relation between the international normalized ratio and the risk of an event was not significantly influenced by the indication for oral anticoagulant therapy, the type of anticoagulant prescribed, or the presence of cancer or renal failure $(p<0.05)$.

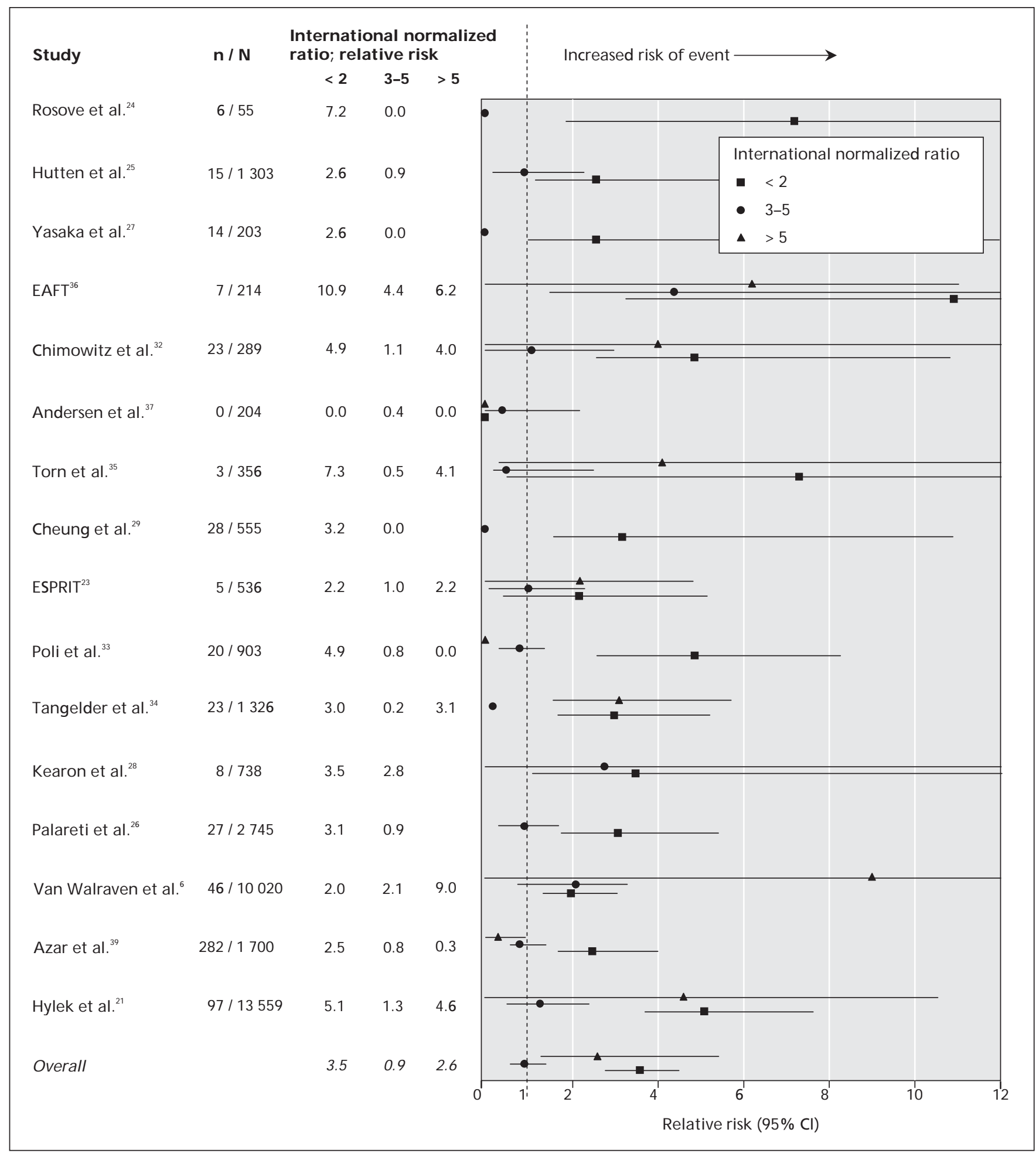

Figure 3: Anticoagulation intensity and risk of thromboembolic events. An international normalized ratio of 2-3 was the reference range. Studies that did not report events at a ratio greater than 5 reported a maximum range of ratio greater than 3 . We grouped these data into the range of 3-5. $\mathrm{Cl}=$ confidence interval, EAFT = European Atrial Fibrillation Trial Study Group, ESPRIT = European and Australian Stroke Prevention in Reversible Ischaemia Trial, RR = relative risk. Confidence intervals are in Appendix 5, available online at www.cmaj.ca/cgi/content/full/179/3/235/DC2. 


\section{Interpretation}

We found a strong association between anticoagulation intensity and the risk of hemorrhagic and thromboembolic events. The risk of hemorrhage significantly increased when the international normalized ratio exceeded 3 . The risk of throm- boemboli was greatest when the ratio was below 2. Overall, patients were safest with a ratio of 2-3.

Numerous studies have shown that patients spend more time with ratios below than above the therapeutic range. ${ }^{6.7}$ This could be partly attributable to an overestimated risk of hemorrhage associated with oral anticoagulant use. Results of

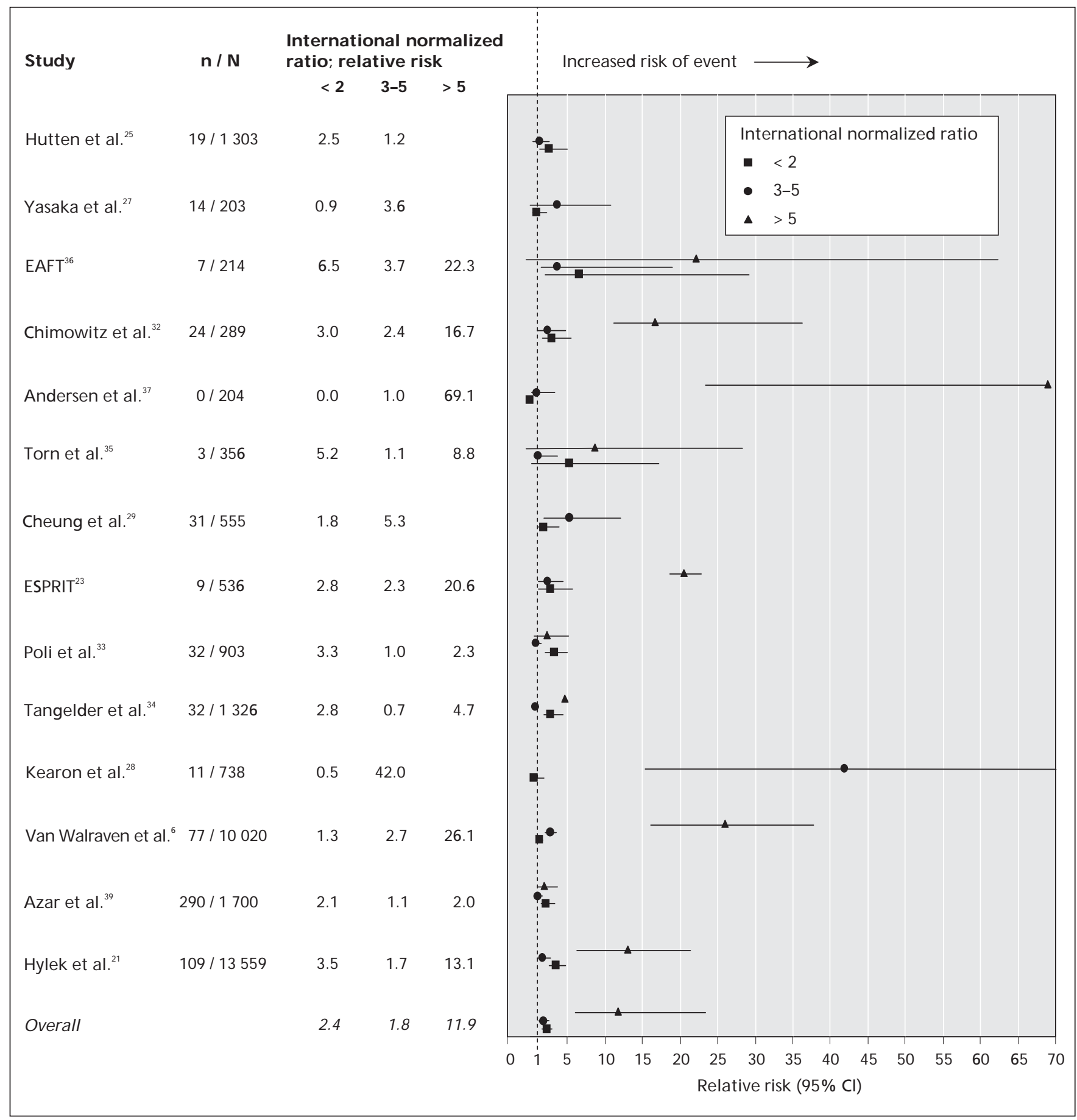

Figure 4: Anticoagulation intensity and risk of hemorrhagic or thromboembolic events combined. An international normalized ratio of 2-3 was the reference range. Studies that did not report events at a ratio greater than 5 reported a maximum range of ratio greater than 3. We grouped these data into the range of 3-5. Cl = confidence interval, EAFT = European Atrial Fibrillation Trial Study Group, ESPRIT = European and Australian Stroke Prevention in Reversible Ischaemia Trial, RR = relative risk. Confidence intervals are in Appendix 5, available online at www.cmaj.ca/cgi/content/full/179/3/235/DC2. 
a survey conducted by Gross and colleagues ${ }^{41}$ showed that physicians' estimates of annual rates of intracranial hemorrhage associated with the use of warfarin were more than 10 times higher than those based on the literature. ${ }^{41}$ When both hemorrhagic and thromboembolic events are considered, our data showed that patients were safer with a ratio slightly above, rather than below, the therapeutic range of 2-3. Physicians should be aware of this finding and should adjust their clinical practices accordingly by aggressively correcting subtherapeutic ratios and avoiding overreaction to ratios that narrowly exceed 3 . More extensive use of computer-based algorithms for does adjustment of anticoagulants could help avoid systemic underanticoagulation. ${ }^{42-46}$

We found that the relative risk of thromboembolic events increased significantly when the international normalized ratio exceeded 5. This reflects the curvilinear association between ratio levels and risk of thromboemboli that we identified in 7 of 16 studies included in our analysis. This curvilinear association could be attributable to high-risk subpopulations of patients, including those with neoplasia, valve replacements and thrombophilic syndromes. Such patients could have higher target ratios, and thus a greater risk of ratios exceeding 5, which, along with a greater risk of thromboemboli in such patients, might explain the curvilinear association that we observed.

Our review has limitations at the study level. First, the number of events at reported ranges of international normalized ratios could be biased since most of the studies failed to assign all events to ranges. Second, the person-years of observation at reported ranges may have been inaccurate. Although linear imputation of ratios between actual measures is an industry standard,,$^{14,47}$ it has some error. ${ }^{14,48}$ It is unlikely that patients' international normalized ratios always vary linearly between actual measures. In addition, 2 studies used imputation methods with error exceeding that of linear interpolation. Only 2 studies captured ratios that were measured outside of the study centre.

Our study also has limitations at the review level. We may have missed eligible studies despite our extensive literature search. More importantly, the studies included in our review were somewhat limited by incomplete reporting. We excluded 8 studies $^{49-56}$ that reported event rates specific to ranges of ratios but that did not provide the number of events and person-years of observation in discrete ranges. Although unlikely, the inclusion of these studies might have changed our results. For example, the relative and absolute risk estimates may have been more precise. Second, we found heterogeneity among the 19 studies, which was not surprising since heterogeneity is expected when observational studies are included in meta-analyses..$^{57}$ Despite the interstudy heterogeneity, we proceeded with the meta-analysis because the generalized estimating equation methodology clusters ranges of international normalized ratios within studies. Such clustering of outcomes takes study heterogeneity into account. Third, we were able to report the absolute and relative risks of events for only 4 clinically relevant ranges of international normalized ratios. Narrower ranges of ratios in our model may have given more precise results. However, our use of 4 ranges is related to how the original data were reported. Finally, since we were dealing with study-level variables, our study had limited power to detect the influence of patient-level variables on the association between anticoagulant intensity and risk of events.

Our study showed a strong and robust association between anticoagulation intensity and clinically relevant outcomes. For the most common indications for anticoagulation, maximizing the length of time at which a patient's international normalized ratio is in the therapeutic range of 2-3 should minimize the risk of both hemorrhagic and thromboembolic events. Avoiding systematic underanticoagulation will also improve patient outcomes.

Our results also have important implications for researchers. They show that researchers must continue to evaluate interventions, including anticoagulation clinics, ${ }^{47,58,59}$ patient self-management ${ }^{60-62}$ and telephone communication systems, ${ }^{63}$ that increase the amount of time at which patients' international normalized ratios are within the therapeutic range.

This article has been peer reviewed.

Competing interests: None declared.

Contributors: Natalie Oake and Carl van Walraven designed this systematic review and meta-analysis. Natalie Oake and Alison Jennings conducted the literature search and were responsible for data abstraction. Alan Forster consulted on clinical content, and Dean Fergusson and Steve Doucette consulted on methodological content. All authors were involved in the analysis and interpretation of data, the writing and revision of the manuscript and approved the final version for publication.

\section{REFERENCES}

1. Levine MN, Raskob G, Beyth RJ, et al. Hemorrhagic complications of anticoagulant treatment: the Seventh ACCP Conference on Antithrombotic and Thrombolytic Therapy. Chest 2004;126:287S-310S

2. Hull R, Hirsh J, Jay R, et al. Different intensities of oral anticoagulant therapy in the treatment of proximal-vein thrombosis. N Engl J Med 1982;307:1676-81.

3. Cannegieter SC, Rosendaal FR, Briet E. Thromboembolic and bleeding complications in patients with mechanical heart valve prostheses. Circulation 1994;89:635-41.

4. Reynolds MW, Fahrbach K, Hauch O, et al. Warfarin anticoagulation and outcomes in patients with atrial fibrillation: a systematic review and meta-analysis. Chest 2004;126:1938-45.

5. Oden A, Fahlen M, Hart RG. Optimal INR for prevention of stroke and death in atrial fibrillation: a critical appraisal. Thromb Res 2006;117:493-9.

6. Van Walraven C, Oake N, Wells PS, et al. Burden of potentially avoidable anticoagulant-associated hemorrhagic and thromboembolic events in the elderly. Chest 2007;131:1508-15.

7. Ansell J, Hollowell J, Pengo V, et al. Descriptive analysis of the process and quality of oral anticoagulation management in real-life practice in patients with chronic non-valvular atrial fibrillation: the international study of anticoagulation management (ISAM). J Thromb Thrombolysis 2007;23:83-91.

8. Larson RJ, Fisher ES. Should aspirin be continued in patients started on warfarin? J Gen Intern Med 2004;19:879-86.

9. Little SH, Massel DR. Antiplatelet and anticoagulation for patients with prosthetic heart valves. Cochrane Database Syst Rev 2003;CD003464.

10. Earle CC, Pham B, Wells GA. An assessment of methods to combine published survival curves. Med Decis Making 2000;20:104-11.

11. Grunkemeier GL, London MR. Reliability of comparative data from different sources. In: Butchart EG, Bodnar E, editors. Thrombosis, embolism, and bleeding. London (UK): ICR Publishers; 1992. p. 464-75.

12. Grunkemeier GL, Wu Y. "Our complication rates are lower than theirs": statistical critique of heart valve comparisons. J Thorac Cardiovasc Surg 2003;125:290-300.

13. Horstkotte D, Schulte HD, Bircks W, et al. Lower intensity anticoagulation therapy results in lower complication rates with the St. Jude Medical prosthesis. J Thorac Cardiovasc Surg 1994;107:1136-45.

14. Hutten BA, Prins MH, Redekop WK, et al. Comparison of three methods to assess therapeutic quality control of treatment with vitamin $\mathrm{K}$ antagonists. Thromb Haemost 1999;82:1260-3.

15. Gardner W, Mulvey EP, Shaw EC. Regression analyses of counts and rates: Poisson, overdispersed Poisson and negative binomial models. Psychol Bull 1995;118:392-404.

16. Diggle PJ, Heagerty PH, Liang K. Analysis of longitudinal data. Oxford (UK): Oxford University Press; 2002. 
17. Guevara JP, Berlin JA, Wolf FM. Meta-analytic methods for pooling rates when follow-up duration varies: a case study. BMC Med Res Methodol 2004;4:17.

18. Hardin JW, Hilbe JM. Generalized estimating equations. Boca Raton (FL): Chapman \& Hall/CRC; 2003.

19. Szklo M, Nieto FJ. Epidemiology: beyond the basics. Sudbury (MA): Jones and Bartlett; 2004.

20. Fang MC, Go AS, Chang Y, et al. Death and disability from warfarin-associated intracranial and extracranial hemorrhages. Am J Med 2007;120:700-5

21. Hylek EM, Go AS, Chang Y, et al. Effect of intensity of oral anticoagulation on stroke severity and mortality in atrial fibrillation. N Engl J Med 2003;349:1019-26.

22. Oden A, Fahlen M. Oral anticoagulation and risk of death: a medical record linkage study. BMJ 2002;325:1073-5.

23. ESPRIT Study Group; Algra A. Medium intensity oral anticoagulants versus aspirin after cerebral ischaemia of arterial origin (ESPRIT): a randomised controlled trial. Lancet Neurol 2007;6:115-24.

24. Rosove MH, Brewer PM. Antiphospholipid thrombosis: clinical course after the first thrombotic event in 70 patients. Ann Intern Med 1992;117:303-8.

25. Hutten BA, Prins MH, Gent M, et al. Incidence of recurrent thromboembolic and bleeding complications among patients with venous thromboembolism in relation to both malignancy and achieved international normalized ratio: a retrospective analysis. J Clin Oncol 2000;18:3078-83.

26. Palareti G, Manotti C, DAngelo A, et al. Thrombotic events during oral anticoagulant treatment: results of the inception-cohort, prospective, collaborative ISCOAT study: ISCOAT study group (Italian Study on Complications of Oral Anticoagulant Therapy). Thromb Haemost 1997;78:1438-43.

27. Yasaka M, Minematsu K, Yamaguchi T. Optimal intensity of international normalized ratio in warfarin therapy for secondary prevention of stroke in patients with non-valvular atrial fibrillation. Intern Med 2001;40:1183-8.

28. Kearon C, Ginsberg JS, Kovacs MJ, et al. Comparison of low-intensity warfarin therapy with conventional-intensity warfarin therapy for long-term prevention of recurrent venous thromboembolism. N Engl J Med 2003;349:631-9.

29. Cheung CM, Tsoi TH, Huang CY. The lowest effective intensity of prophylactic anticoagulation for patients with atrial fibrillation. Cerebrovasc Dis 2005;20:114-9.

30. MacCallum PK, Brennan PJ, Meade TW. Minimum effective intensity of oral anticoagulant therapy in primary prevention of coronary heart disease. Arch Intern Med 2000;160:2462-8.

31. Ten Berg JM, Hutten BA, Kelder JC, et al. Oral anticoagulant therapy during and after coronary angioplasty the intensity and duration of anticoagulation are essential to reduce thrombotic complications. Circulation 2001;103:2042-7.

32. Chimowitz MI, Lynn MJ, Howlett-Smith H, et al. Comparison of warfarin and aspirin for symptomatic intracranial arterial stenosis. N Engl J Med 2005;352:1305-16.

33. Poli D, Antonucci E, Lombardi A, et al. Low rate of bleeding and thrombotic complications of oral anticoagulant therapy independent of age in the real-practice of an anticoagulation clinic. Blood Coagul Fibrinolysis 2003;14:269-75.

34. Tangelder MJD, Algra A, Lawson JA, et al. Optimal oral anticoagulant intensity to prevent secondary ischemic and hemorrhagic events in patients after infrainguinal bypass graft surgery. $J$ Vasc Surg 2001;33:522-7.

35. Torn M, Algra A, Rosendaal FR. Oral anticoagulation for cerebral ischemia of arterial origin: high initial bleeding risk. Neurology 2001;57:1993-9.

36. Optimal oral anticoagulant therapy in patients with nonrheumatic atrial fibrillation and recent cerebral ischemia. The European Atrial Fibrillation Trial Study Group. N Engl J Med 1995;333:5-10.

37. Andersen PV, Aagaard J. Low-dose warfarin in patients with Carbomedics heart valve prostheses. Asian Cardiovasc Thorac Ann 2000;8:11-4.

38. Palareti G, Leali N, Coccheri S, et al. Bleeding complications of oral anticoagulan treatment: an inception-cohort, prospective collaborative study (ISCOAT). Italian Study on Complications of Oral Anticoagulant Therapy. Lancet 1996;348:423-8.

39. Azar AJ, Cannegieter SC, Deckers JW, et al. Optimal intensity of oral anticoagulant therapy after myocardial infarction. J Am Coll Cardiol 1996;27:1349-55.

40. Casais P, Luceros AS, Meschengieser S, et al. Bleeding risk factors in chronic oral anticoagulation with acenocoumarol. Am J Hematol 2000;63:192-6.

41. Gross CP, Vogel EW, Dhond AJ, et al. Factors influencing physicians' reported use of anticoagulation therapy in nonvalvular atrial fibrillation: a cross-sectional survey. Clin Ther 2003;25:1750-64.

42. Vadher BD, Patterson DL, Leaning M, et al. Comparison of oral anticoagulant control by a nurse practitioner using a computer decision-support system with that by clinicians. Clin Lab Haematol 1997;19:203-7.
43. Fitzmaurice DA, Hobbs FD, Murray ET, et al. Evaluation of computerized decision support for oral anticoagulation management based in primary care. Br J Gen Pract 1996;46:533-5.

44. Poller L, Shiach CR, MacCallum PK, et al. Multicentre randomised study of computerised anticoagulant dosage. European Concerted Action on Anticoagulation. Lancet 1998;352:1505-9.

45. Fitzmaurice DA, Hobbs FD, Murray ET, et al. Oral anticoagulation management in primary care with the use of computerized decision support and near-patient testing: a randomized, controlled trial. Arch Intern Med 2000;160:2343-8.

46. Manotti C, Moia M, Palareti G, et al. Effect of computer-aided management on the quality of treatment in anticoagulated patients: a prospective, randomized, multicenter trial of APROAT (Automated PRogram for Oral Anticoagulant Treatment). Haematologica 2001;86:1060-70.

47. Van Walraven C, Jennings A, Oake N, et al. Effect of study setting on anticoagulation control: a systematic review and metaregression. Chest 2006;129:1155-66.

48. Azar AJ, Deckers JW, Rosendaal FR, et al. Assessment of therapeutic quality control in a long-term anticoagulant trial in post-myocardial infarction patients. Thromb Haemost 1994;72:347-51.

49. You JHS, Chan FWH, Wong RSM, et al. Is INR between 2.0 and 3.0 the optimal level for Chinese patients on warfarin therapy for moderate-intensity anticoagulation? Br J Clin Pharmacol 2005;59:582-7.

50. A randomized trial of anticoagulants versus aspirin after cerebral ischemia of presumed arterial origin. The Stroke Prevention in Reversible Ischemia Trial (SPIRIT) Study Group. Ann Neurol 1997;42:857-65.

51. Veeger NJ, Piersma-Wichers M, Tijssen JG, et al. van der MJ. Individual time within target range in patients treated with vitamin $\mathrm{K}$ antagonists: main determinant of quality of anticoagulation and predictor of clinical outcome. A retrospective study of 2300 consecutive patients with venous thromboembolism. $\mathrm{BrJ}$ Haematol 2005;128:513-9.

52. Mohr JP, Thompson JL, Lazar RM, et al. A comparison of warfarin and aspirin for the prevention of recurrent ischemic stroke. N Engl J Med 2001;345:1444-51.

53. Nozawa T, Asanoi H, Inoue H. TOWARD Investigators. Toyama Warfarin Rational Dosage. Instability of anticoagulation intensity contributes to occurrence of ischemic stroke in patients with non-rheumatic atrial fibrillation. Jpn Circ J 2001;65:404-8.

54. Van der Meer FJ, Rosendaal FR, Vandenbroucke JP, et al. Bleeding complications in oral anticoagulant therapy. An analysis of risk factors. Arch Intern Med 1993; $153: 1557-62$

55. Adjusted-dose warfarin versus low-intensity, fixed-dose warfarin plus aspirin for high-risk patients with atrial fibrillation: Stroke Prevention in Atrial Fibrillation III randomised clinical trial. Lancet 1996;348:633-8.

56. Cannegieter SC, Rosendaal FR, Wintzen AR, et al. Optimal oral anticoagulant therapy in patients with mechanical heart valves. $N$ Engl J Med 1995;333:11-7.

57. Berlin JA. Invited commentary: benefits of heterogeneity in meta-analysis of data from epidemiologic studies. Am J Epidemiol 1995;142:383-7.

58. Chamberlain MA, Sageser NA, Ruiz D. Comparison of anticoagulation clinic patient outcomes with outcomes from traditional care in a family medicine clinic. $J$ Am Board Fam Pract 2001;14:16-21.

59. Foss MT, Schoch PH, Sintek CD. Efficient operation of a high-volume anticoagulation clinic. Am J Health Syst Pharm 1999;56:443-9.

60. Hasenkam JM, Kimose HH, Knudsen L, et al. Self management of oral anticoagulant therapy after heart valve replacement. Eur J Cardiothorac Surg 1997;11:935-42.

61. Horstkotte D, Piper C, Wiemer M. Improvement of prognosis by home prothrombin estimation in patients with life-long anticoagulant therapy. Eur Heart J 1996; (suppl. 17):230.

62. Sawicki PT. A structured teaching and self-management program for patients receiving oral anticoagulation: a randomized controlled trial. Working Group for the Study of Patient Self-Management of Oral Anticoagulation. JAMA 1999;281:145-50.

63. Staresinic AG, Sorkness CA, Goodman BM, et al. Comparison of outcomes using 2 delivery models of anticoagulation care. Arch Intern Med 2006;166:997-1002.

\section{Correspondence to: Dr. Carl van Walraven, Clinical} Epidemiology Program, Ottawa Health Research Institute, Rm. ASB1-003, Ottawa Hospital, Civic Campus, 1053 Carling Ave., Ottawa ON K1Y4E9; fax 613 761-5355; carlv@ohri.ca 